\title{
Universal free school meals through the Community Eligibility Provision: Maryland food service provider perspectives
}

\author{
Amelie A. Hecht ${ }^{a} *$ and Roni A. Neff ${ }^{b}$ \\ Johns Hopkins Bloomberg School of Public Health \\ Tam Lynne Kelley ${ }^{\mathrm{c}}$ \\ No Kid Hungry Maryland \\ Keshia M. Pollack Porter ${ }^{\mathrm{d}}$ \\ Johns Hopkins Bloomberg School of Public Health
}

Submitted September 18, 2020 / Revised December 3 and December 18, 2020 / Accepted December 18, 2020 /

Published online April 9, 2021

Citation: Hecht, A. A., Neff, R. A., Kelley, T. L., \& Pollack Porter, K. M. (2021). Universal free school meals through the Community Eligibility Provision: Maryland food service provider perspectives. Journal of Agriculture, Food Systems, and Community Development, 10(2), 529-550. https://doi.org/10.5304/jafscd.2021.102.033

Copyright (C) 2021 by the Authors. Published by the Lyson Center for Civic Agriculture and Food Systems. Open access under CC-BY license.

\author{
Abstract \\ Since 2014, the Community Eligibility Provision \\ (CEP) school meal funding option has enabled \\ high-poverty schools nationwide to serve universal \\ a* Corresponding author: Amelie A. Hecht, Research Associate, \\ Department of Health Policy and Management, Johns \\ Hopkins Bloomberg School of Public Health. \\ Amelie A. Hecht is now National Poverty Fellow, Institute \\ for Research on Poverty, University of Wisconsin-Madison; \\ 1180 Observatory Drive; 3412 William H. Sewell Social \\ Sciences Building; Madison, WI 53706-1320 USA; \\ AHecht3@jhu.edu \\ b Roni A. Neff, Associate Professor, Department of \\ Environmental Health and Engineering, Center for a Livable \\ Future, Johns Hopkins Bloomberg School of Public Health; \\ RNeff1@jhu.edu \\ c Tam Lynne Kelley, Senior Manager, No Kid Hungry \\ Maryland; TKelley@strength.org \\ d Keshia M. Pollack Porter, Professor, Department of Health \\ Policy and Management, Johns Hopkins Bloomberg School of \\ Public Health; kpollac1@jhu.edu
}

free breakfast and lunch. Evidence suggests that CEP has benefits for student meal participation, behavior, and academic performance. This qualitative study explores perspectives among food service staff $(n=28)$ in CEP-participating school districts in Maryland on (1) implementation barriers, (2) implementation best practices, and

\section{Author Note}

This study was completed as part of a doctoral dissertation. The authors have no conflicts of interest to disclose.

\section{Funding Disclosure}

AAH was supported by the Center for a Livable FutureLerner Fellowship and the Johns Hopkins Lerner Center for Public Health Promotion. This project is supported by the Health Resources and Services Administration (HRSA) of the U.S. Department of Health and Human Services (HHS) under grant number 1 UB6HP31689-01-00 "Public Health Training Centers" for US $\$ 3,699,596$. This information or content and conclusions are those of the author and should not be construed as the official position or policy of, nor should any endorsements be inferred by HRSA, HHS or the U.S. Government. 
(3) impacts on students, school operations, and the broader food system. Perceived benefits of CEP include increased meal participation, reduced student stigma and financial stress among parents, and improved staff morale. Most participants did not report any change in wasted food or relationships with local or regional farms associated with CEP adoption. Implementation barriers, including concerns regarding CEP's impact on federal, state, and grant education funding, provide insight into potential policy interventions that may promote uptake. Best practices, including strong communication with parents and creative strategies to boost student meal participation, can be adopted by other districts.

\section{Keywords}

Community Eligibility Provision, Food Waste, Implementation Science, Nutrition Policy, School Meals, Universal Free Meals, Wasted Food

\section{Introduction}

Among children, food insecurity, defined as limited or uncertain access to nutritionally adequate, safe, and acceptable foods (U.S. Department of Agriculture, Economic Research Service [USDA ERS], 2019), is associated with developmental delay and poor academic performance, including low test scores and attendance rates (Alaimo, Olson, \& Frongillo, 2001; Glewwe, Jacoby, \& King, 2001; Jyoti, Frongillo, \& Jones, 2005). Food insecurity is also associated with a range of adverse physical and mental health outcomes (Alaimo, Olson, Frongillo, \& Briefel, 2001; Cook \& Frank, 2008; Gundersen \& Ziliak, 2015; Ryu \& Bartfeld, 2012; Weinreb et al., 2002). In 2018, one in seven U.S. households with children experienced food insecurity (USDA ERS, 2019). Estimates suggest that since the beginning of the COVID-19 pandemic, rates of food insecurity for households with children have doubled (Bauer, 2020).

Two federal school-based nutrition programs of the U.S. Department of Agriculture (USDA) the National School Lunch Program and School Breakfast Program - have been consistently shown to decrease household food insecurity (Bartfeld \& Ahn, 2011; Huang \& Barnidge, 2016). Through these programs, in 2019, nearly 30 million lunches and 15 million breakfasts were served each day at low or no cost to students (USDA ERS, 2019). Prior to the COVID-19 pandemic, almost half of U.S. public school students qualified to receive free meals (because their household incomes were below $130 \%$ of the federal poverty level) or reduced-price meals (because their household incomes were between $130 \%$ and $185 \%$ of the federal poverty level) (Fox \& Gearan, 2019). With the recent rise in unemployment, particularly among racially and ethnically diverse populations, the number of children eligible for free or reducedprice meals (FRPM) is now likely much higher (Congressional Research Service, 2020). Despite high rates of food insecurity among FRPM-eligible students, school meal participation among eligible students has been low: in 2015, 43\% of eligible students participated in school breakfast and 81\% participated in school lunch (Fox \& Gearan, 2019). Barriers to participation in school meal programs include stigma among students and challenges for parents completing meal applications due to limited English language or literacy skills (Moore, Hulsey, \& Ponza, 2009; Poppendieck, 2010).

To address these barriers, as part of the Healthy, Hunger-Free Kids Act of 2010, Congress authorized the Community Eligibility Provision (CEP) (Public Law 111-296. Healthy Hunger-Free Kids Act of 2010, 42 USC 1751, \$203., 2010). High-poverty schools that opt into CEP serve universal free breakfast and lunch to all students, regardless of household income. CEP is an alternative to the traditional USDA model of using applications to certify students annually for FRPM based on household size and income.

Individual schools, groups of schools, or entire school districts can opt into CEP if their aggregate identified student percentage (ISP) is $40 \%$ or greater. The ISP is the percent of students directly certified for free meals based on existing administrative data, such as participation in the Supplemental Nutrition Assistance Program (SNAP). State education agencies conduct direct certification data matching between school enrollment lists and existing administrative databases at least once per year and are required to notify districts which schools are eligible or neareligible for CEP each spring. Participating schools 
must be recertified for CEP every four years.

In CEP schools, federal meal reimbursement rates are calculated based on the ISP. The ISP multiplied by 1.6 determines the percentage of meals served that are reimbursed at the "free" rate (on average, $\$ 3.41$ for lunch, ${ }^{1} \$ 1.84$ for breakfast), while the remainder of meals served are reimbursed at the lower "paid" rate (on average, $\$ 0.32$ for lunch, $\$ 0.31$ for breakfast) (School Nutrition Association, 2019). For example, a school with an ISP of $62.5 \%$ would be reimbursed at the "free meal" rate for all meals served $(62.5 \%$ x $1.6=$ $100 \%$ ), whereas a school with an ISP of $50 \%$ would be reimbursed at the "free" rate for $80 \%$ of meals served $(50 \% \times 1.6=80 \%)$, and at the "paid" rate for the remaining $20 \%$ of meals served. Schools with ISPs below $62.5 \%$ aim to make up the difference in federal reimbursement through reduced administrative overhead and improved meal participation, leading to greater economies of scale.

CEP was phased in over a three-year period in 10 states and the District of Columbia, and then became available nationwide beginning in school year (SY) 2014-15. By SY 2019-20, 30,667 schools, or approximately two-thirds of eligible schools, offered CEP, serving 14.9 million children (Food Research \& Action Center, 2020). Maryland began offering CEP in SY 2013-14, the third year of the phase-in period. In Maryland, six public schools participated in CEP in the first year it was available and 24 participated the next year. Maryland schools were hesitant to adopt CEP due to uncertainty about how it could impact state compensatory education funding: under CEP, schools no longer collect applications for FRPM, which provide data that the state has historically used to determine compensatory education funding levels for schools (Maryland State Department of Education, 2015). Maryland allocates approximately $\$ 1.3$ billion annually in state compensatory education funding to schools that serve a high proportion of economically disadvantaged students (Maryland Association of Boards of Education, 2019). To address concerns regarding potential loss of funding, in May 2015, the Maryland General Assembly enacted the Hunger-Free Schools Act of 2015, which guaranteed a minimum state compensatory education funding rate for schools participating in CEP (The Hunger-Free Schools Act of 2015; Maryland HB $965,2015)$. By the following year (SY 2015-16), 198 new schools had opted into CEP. By SY 201920, 236 Maryland public schools were participating in CEP; there were 63 individually eligible schools (schools with ISPs $40 \%$ or greater) that did not participate (Maryland State Department of Education, 2020a).

A growing body of literature has explored the impact of universal free meals on student health, behavior, and academic performance. A recent synthesis of quantitative studies evaluating universal free meal programs, including CEP, found strong evidence of increased meal participation rates; limited but promising evidence of benefits for ontime grade promotion, food security, and weight outcomes; and mixed evidence of improvements in attendance and test scores (Hecht, Pollack Porter, \& Turner, 2020). The impact of universal free meal programs on the broader food system is understudied. Two previous studies have considered the relationship between universal free breakfast programs and wasted food; in both, food service staff reported perceived increased food waste associated with the program implementation (Bernstein, McLaughlin, Crepinsek, \& Daft, 2004; Blondin, Djang, Metayer, Anzman-Frasca, \& Economos, 2015). The impact of universal free meal programs on the relationships between schools and their local or regional farmers has not been examined in the literature.

Only one study to-date has qualitatively explored perceived barriers to CEP implementation (Logan et al., 2014). That study, published by the USDA in 2014, focused on states participating in the phase-in period and included surveys of district administrators and interviews with State Child Nutrition Agency directors. The study found that two leading barriers to implementation were lack of time during the initial implementation period for districts to learn about CEP and the uncertainty about the financial implications of CEP both for meal reimbursement and for education funding

\footnotetext{
${ }^{1}$ All currencies in this article are in U.S. dollars.
} 
traditionally allocated based on FRPM data. While the USDA has since worked to provide guidance to eligible schools about CEP and its potential financial impacts (USDA Food and Nutrition Service, 2015), these and other barriers may persist.

This study assesses perspectives on barriers and facilitators to CEP implementation among food service staff in districts that have adopted CEP in Maryland. The focus is on barriers to implementation that may be addressed through policy or programmatic changes, as well as best practices that can be used by other school and district administrators across the country. Further, this study explores perspectives on how CEP may influence the broader food system, including wasted food and relationships between schools and local farmers. Findings may help guide targeted strategies by advocates, policymakers, and state education agencies to promote CEP uptake and ease implementation.

\section{Methods}

\section{Recruitment and Sampling}

Semistructured in-depth interviews $(n=28)$ were conducted with food service staff in Maryland schools and districts participating in CEP stratified by two informant categories: 9 food service directors (FSDs) at the district level and 19 cafeteria managers (CMs) at the school level. Both FSDs and CMs were interviewed in order to gain a holistic picture of CEP implementation at the administrative and school levels. In many school districts, CMs are responsible for overseeing day-to-day meal service operations, as well as inventory management and staffing for their school cafeteria. FSDs work closely with CMs to oversee the budget and strategic operations for all school cafeterias in their district, including menu planning and communication with families. In most districts, FSDs play an important role in deciding whether and how to implement CEP. Under the traditional USDA reimbursement model, FRPM applications are also typically processed centrally in the district office.

In Maryland, 12 public school districts and 240 public schools participated in CEP during SY 2018-19. A list of all CEP participating schools in SY 2018-19 was retrieved from the Maryland State
Department of Education website (Maryland State Department of Education, 2020a). Twelve FSDs, one from each participating district, were invited to participate in this study. A separate CM sampling frame was created with CMs from all 240 participating schools. To provide insight into how implementation potentially differed across school levels and geographies, the CM sampling frame was stratified by school level based on National Center for Education Statistics classification (elementary, middle, high, other [e.g., grades K-12]) and district to create 48 mutually exclusive and exhaustive strata (National Center for Education Statistics, US Department of Education, 2020) (Table 1). Twenty-two of these strata had no schools-for example, in four counties, only elementary schools participated in CEP, so the middle school, high school, and other school strata were empty. Using a random number generator, one $\mathrm{CM}$ from each of the 26 remaining strata was sampled. Between one and four CMs were interviewed per district: in districts with schools from only one stratum (e.g., only elementary schools) participating in CEP, one $\mathrm{CM}$ was sampled, and in districts with schools at all four levels participating in CEP, four CMs were sampled. If a CM declined to participate or was unreachable after six attempts via email or telephone, a new $\mathrm{CM}$ within the same stratum was randomly selected, if available. Participants were eligible if they were $\geq 18$ years, could speak English, and worked at a CEP-participating school or district.

The overall response rate was $76 \%$. Three FSDs declined to participate; one cited a district policy limiting outside research and two did not provide a reason. In one district where the FSD declined to participate, researchers were asked not to contact the CMs. In the two other districts where FSDs refused, two CMs declined to participate without explicit permission from the FSD, and there were no other $\mathrm{CMs}$ in the same stratum to sample. In another district, two CMs were unable to be reached but were replaced by CMs in the same stratum.

\section{Data Collection}

Semistructured in-depth interviews were conducted from July 2019 to February 2020. An interview guide was developed based on a review of the liter- 
Table 1. Participating Food Service Directors and Cafeteria Managers by District and School Level a ( $n=28$ participants)

\begin{tabular}{|c|c|c|c|c|c|}
\hline School District & $\begin{array}{l}\text { Food Service } \\
\text { Director }\end{array}$ & $\begin{array}{l}\text { Elementary School } \\
\text { Cafeteria Manager }\end{array}$ & $\begin{array}{c}\text { Middle School } \\
\text { Cafeteria Manager }\end{array}$ & $\begin{array}{c}\text { High School } \\
\text { Cafeteria Manager }\end{array}$ & $\begin{array}{c}\text { Other School }{ }^{b} \\
\text { Cafeteria Manager }\end{array}$ \\
\hline County A & $\checkmark$ & $\checkmark$ & $\mathrm{N} / \mathrm{A}$ & $\mathrm{N} / \mathrm{A}$ & $\mathrm{N} / \mathrm{A}$ \\
\hline County B & $\checkmark$ & $\checkmark$ & $\checkmark$ & $\checkmark$ & $\checkmark$ \\
\hline County C & $x$ & $x$ & $x$ & $x$ & $x$ \\
\hline County D & $\checkmark$ & $\checkmark$ & $\mathrm{N} / \mathrm{A}$ & $\mathrm{N} / \mathrm{A}$ & $\mathrm{N} / \mathrm{A}$ \\
\hline County E & $\checkmark$ & $\checkmark$ & $\checkmark$ & $\checkmark$ & $\mathrm{N} / \mathrm{A}$ \\
\hline County F & $\checkmark$ & $\checkmark$ & $\checkmark$ & $\checkmark$ & N/A \\
\hline County G & $\checkmark$ & $\mathrm{N} / \mathrm{A}$ & $\mathrm{N} / \mathrm{A}$ & $\mathrm{N} / \mathrm{A}$ & $\checkmark$ \\
\hline County H & $x$ & $\checkmark$ & $x$ & $\mathrm{~N} / \mathrm{A}$ & N/A \\
\hline County I & $\checkmark$ & $\checkmark$ & $\mathrm{N} / \mathrm{A}$ & $\mathrm{N} / \mathrm{A}$ & N/A \\
\hline County J & $x$ & $\checkmark$ & $x$ & $\checkmark$ & N/A \\
\hline County K & $\checkmark$ & $\checkmark$ & N/A & $\mathrm{N} / \mathrm{A}$ & $\checkmark$ \\
\hline County L & $\checkmark$ & $\checkmark$ & $\mathrm{N} / \mathrm{A}$ & $\mathrm{N} / \mathrm{A}$ & $\mathrm{N} / \mathrm{A}$ \\
\hline Total participating & 9 & 10 & 3 & 4 & 3 \\
\hline
\end{tabular}

a Check mark indicates a participant from the stratum participated in the study. $\mathrm{X}$ indicates no participant in the stratum participated in the study. N/A indicates there was no school within the stratum to sample. A total of 19 cafeteria managers were interviewed representing 20 schools (one cafeteria manager served two schools).

b Other school level (e.g., K-12)

ature related to policy implementation and school nutrition (see the Appendix). Eight experts from across the country reviewed the interview guide for content validity. The interview guide was pilot tested for clarity and ease of administration with two FSDs at districts implementing CEP outside of Maryland and was revised based on their feedback.

CMs were asked about the process of implementing CEP at their school and factors that facilitated or hindered implementation. They were also asked about perceived consequences of CEP implementation, including impacts on cafeteria operations, staff workload, staff morale, student behavior, wasted food, and purchasing relationships with local or regional farmers. FSDs were asked the same questions, plus questions related to why the district decided to implement CEP, who was involved in the decision to implement CEP, and the budgetary impacts of CEP.

Interviews occurred by phone and lasted 30-55 minutes. All participants provided informed verbal consent. Recordings were transcribed by a third party and all identifying information was redacted prior to analysis. Participants received $\$ 20$ gift cards. This study was reviewed and determined to be non-human subjects research by the Johns Hopkins Bloomberg School of Public Health Institutional Review Board. The Institutional Review Board for Baltimore City Public Schools also approved this study (IRB \#2019-074).

\section{Data Analysis}

Data were analyzed using ATLAS.ti (version 6.0, ATLAS.ti GmbH, Berlin, Germany). Using a phronetic iterative approach (Tracy, 2013), the research team developed an analytic codebook composed of 8 coding families and 105 codes. Two researchers coded transcripts, meeting regularly to discuss findings and reconcile differences. After coding, data were extracted and analyzed. Relevant codes were categorized according to emergent themes, which were mapped onto the Consolidated Framework for Implementation Research (Keith, Crosson, O’Malley, Cromp, \& Taylor, 2017). This 
framework was selected because of its focus on identifying actionable findings to improve implementation. The framework outlines five major domains that may impact implementation: the intervention characteristics, the inner setting (i.e., features of the implementing organization), the outer setting (i.e., features of the external context or environment), characteristics of individuals involved in implementation, and the implementation process (i.e., strategies or tactics that might influence implementation). There were no strong themes uniquely related to one domain-characteristics of individuals involved in implementation; thus, this domain was eliminated, and findings presented below are organized according to the remaining four domains.

\section{Results}

\section{Participant Characteristics}

Nine FSDs and 19 CMs participated in this study, representing 10 school districts (in one district, an FSD declined to participate, but CMs from the district participated) and 20 schools (one CM served two schools). Characteristics of participating FSDs, $\mathrm{CMs}$, and the districts and schools they represented are summarized in Table 2 . All three districts in

Table 2. Characteristics of Participating Food Service Directors and Cafeteria Managers $(n=28)$ and the Districts and Schools They Represent

\begin{tabular}{|c|c|}
\hline \multicolumn{2}{|l|}{ Food service director $(n=9)$} \\
\hline Years in current role, mean (range) & $7.9(2-21)$ \\
\hline Years in school food service, mean (range) & $11.8(5-21)$ \\
\hline \multicolumn{2}{|l|}{ Districts represented by food service directors $(n=10)^{\mathrm{a}}$} \\
\hline Years since first school in the district adopted Community Eligibility Provision, mean (range) & $4.7(2-7)$ \\
\hline District-wide adoption, $\mathrm{n}$ & 3 \\
\hline \multicolumn{2}{|l|}{ Cafeteria manager $(n=19)$} \\
\hline Years in current role, mean (range) & $10.3(1-27)$ \\
\hline Years in school food service, mean (range) & $16.3(1-36)$ \\
\hline \multicolumn{2}{|l|}{ Schools represented by cafeteria managers $(n=20)^{b}$} \\
\hline Years since school adopted Community Eligibility Provision, mean (range) & $5(2-7)$ \\
\hline \multicolumn{2}{|l|}{ School level $(n)$} \\
\hline Elementary & 10 \\
\hline Middle & 3 \\
\hline High & 4 \\
\hline Other & 3 \\
\hline Maryland Meals for Achievement participant prior to adoption of the Community Eligibility Provisionc $(n)$ & 9 \\
\hline Funded through Title $\mathrm{I}^{\mathrm{d}}(n)$ & 13 \\
\hline Charter (n) & 1 \\
\hline \multicolumn{2}{|l|}{ Locale $(n)$} \\
\hline Urban & 10 \\
\hline Suburban & 3 \\
\hline Town & 4 \\
\hline Rural & 3 \\
\hline
\end{tabular}

a Ten districts were represented in this study. In one district, the FSD declined to participate, but two CMs participated.

b A total of 19 cafeteria managers were interviewed representing 20 schools (one cafeteria manager served two schools).

c Maryland Meals for Achievement is a universal free breakfast in the classroom program in Maryland that pre-dated the Community Eligibility Provision.

d Title I of the Elementary and Secondary Education Act provides financial support for academic programming in schools with a high percentage of families with low income.

e Locale is classified according to the National Center for Education Statistics designation. 
Maryland that had opted into CEP districtwide were represented. Nine CMs worked in schools that, in the year prior to adopting CEP, participated in Maryland Meals for Achievement, a universal free breakfast in the classroom program in Maryland that launched in 1998 (Maryland State Department of Education, 2020b).

\section{Barriers and Best Practices for Implementation} FSDs and CMs discussed perceived impacts of CEP and factors that may impact ease of CEP implementation at each level of the adapted Consolidated Framework for Implementation Research. FSDs and CMs also outlined best practices for CEP implementation. (Table 3).

Intervention Characteristics: Perceived Relative Advantages and Disadvantages of CEP

Stakeholder perceptions of the CEP program itself, including of its complexity and advantages relative to the traditional meal reimbursement model, may influence implementation (Keith et al., 2017). This section presents FSD and CM perceptions of CEP's relative advantages and disadvantages, including its impact on cafeteria operations, menu offerings, wasted food, student and staff morale, parental financial stress, and the broader school community.

Perceived impact on cafeteria operations. Overall, attitudes toward CEP were positive across participating FSDs and CMs. Most FSDs characterized CEP as an administrative change, with few implementation challenges and little ongoing required maintenance. Most FSDs reported that the decision to adopt CEP was based primarily on financial considerations, coupled with a desire to feed hungry students. In Maryland school districts, Food and Nutrition Services operate financially independently from the rest of the district and FSDs are responsible for maintaining a balanced budget. One FSD highlighted the importance of the bottom line when considering adopting CEP:

You know, we balance many facets of feeding kids and balancing budgets and pleasing parents and Board members and public, and health and wellness, nutrition. There's a lot of facets that you have to balance, but, at the end of the day, it is a business. - FSD 7

Table 3. Cafeteria Manager and Food Service Director $(n=28)$ Recommendations for Community Eligibility Provision (CEP) Implementation Best Practices

\section{Recommendations when considering adopting CEP}

Adopt the CEP district-wide, if possible, even if the district aggregate identified student percentage will not yield reimbursement for all meals at the higher reimbursed "free" rate, as savings in administrative overhead and economies of scale may make district-wide adoption financially feasible.

If district-wide adoption is not possible, pilot the CEP in a small number of schools and closely monitor the financial impacts.

Adopt the CEP in schools that feed into one another to reduce parental confusion by ensuring that siblings are in schools with the same CEP status, and that students in participating elementary or middle schools advance to participating middle or high schools, respectively.

Use resources such as food service directors in other districts and administrators at the state education agency, as well as online resources from U.S. Department of Agriculture and the Food Research \& Action Center.

Recommendations once the decision to adopt CEP has been made

Communicate clearly with parents, administrators, and the broader community to reduce confusion and generate buy-in.

In the first few weeks after the CEP is introduced, order extra food and monitor participation closely; adjust ordering and staffing accordingly.

Boost student participation using innovative strategies such as improved menus and classroom parties while weighing potential impacts on health and nutrition.

Eliminate PINs and switch to a headcount process, which may lead to faster lines and more time for children to eat. 
For adopting schools, CEP impacted both revenue (e.g., federal meal reimbursement and sales of à la carte menu items [snacks and entrees sold separately from the main meal service]) and expenditures (e.g., food, labor, and equipment costs). Most FSDs reported positive budget impacts associated with CEP participation; however, two FSDs reported losing money due to CEP. One of the FSDs who reported a financial loss explained that in their first four-year CEP cycle, they had a higher aggregate ISP, and thus a higher reimbursement level, which led to a budget surplus. The FSD went on to say that since recertifying with a lower ISP, they have run a deficit. The second FSD who reported a loss stated that their Board of Education subsidizes their budget deficit associated with CEP participation, a cost the Board knew it would incur when it decided to adopt CEP but considered worthwhile. Districts that experienced budget gains have used that money to pay down past debts or reinvest in their program. One FSD described how their district handled its budget surplus:

It helps to support some of the [non-CEP] schools that maybe don't do as financially well ... So a lot of this extra revenue is going just to that. We're buying new ovens. We're buying new refrigeration. We're buying new serving lines, serving lines that are breaking down and falling apart. So, all that extra revenue is going right back into our program and mostly going back into our infrastructure. - FSD 3

Some financial savings associated with CEP may come from reduced administrative overhead. Most FSDs reported that CEP has decreased the amount of time and money they spend collecting, processing, and verifying FRPM applications. Reductions in administrative burden appeared to be greater among districts that opted in district-wide, and lower among districts in which only a small proportion of schools participate in CEP.

Nearly all FSDs and CMs reported that CEP led to increased student participation in school meals, especially lunch. A few FSDs and CMs noted that gains in participation were concentrated among students who were previously eligible for reduced-price meals or with household incomes at the borderline for FRPM eligibility.

I would say that our participation probably jumped up about 10 percentage points, because more reduced kids and full-pay kids that maybe didn't buy lunch decided, 'Well, I'll get a lunch if it's free.' ... It was a bit of a savings for them at home. - FSD 3

Notably, however, most CMs at schools that were previously participating in the Maryland Meals for Achievement universal free breakfast in the classroom program reported small or no gains in breakfast participation. Additionally, several CMs in schools that had very high meal participation rates prior to CEP adoption reported small or no gains in meal participation. One CM at a school that offered meals prepared off-site noted that their school did not experience a change in participation, which the CM attributed to students "hating" the school food.

Most CMs reported their total workload had stayed the same or decreased due to CEP. Many CMs reported that CEP streamlined their interactions with students at the point-of-service by removing the need to collect and process cash payments and eliminated the need to call or send letters home to parents of students with unpaid meal debt. A small number of CMs, however, reported that because CEP increased the total number of students participating in school meals, their staff experienced an increase in total workload associated with preparing more meals. With a few exceptions, most of these CMs added that staffing increased correspondingly (either by hiring new employees or transitioning part-time staff to full-time) to accommodate the increased meal participation rates.

Even considering the increases in student meal participation, about half of FSDs and CMs reported that the lunch line moved faster because cafeteria staff no longer needed to process payments. Some schools switched from requiring students to enter PINs to using a simple headcount to track the total number of students participating in meals; CMs at these schools more frequently re- 
ported faster line flow and more time for students to eat their meals.

Districts that continue to use PINs explained that they did so in order to track students with allergies or to maintain the habit of entering PINs, in case a student transfers or advances to another school in the district without CEP. Only one FSD reported slower lines due to increased student participation; that FSD's district continued to use PINs at the point-of-service.

Perceived impact on menu offerings and wasted food. With a few notable exceptions, most FSDs and CMs did not report a change due to CEP to the healthfulness of the menu, the types of foods that students were served and ate, or the practices or policies related to purchasing from local and regional farmers. In most districts, menus are set at the district level, leaving CMs in CEP schools little flexibility to customize the menu. Two CMs, however, reported that with the introduction of breakfast in the classroom and grab-and-go breakfast service (changes that were implemented to increase participation), their schools began to serve more packaged and processed foods, which they perceived to be easier to distribute, but often less healthy. On the other hand, one FSD reported an increase in the total volume of fruits and vegetables they were able to purchase from local farmers due to increased student meal participation. Another FSD reported that due to increased revenue associated with CEP, they were able to offer healthier items that were previously too expensive.

While most FSDs and CMs reported no difference in the perceived amount of food that students wasted following adoption of CEP, there were both reports of positive and negative changes from a small number of participants. One FSD reported less wasted food in their district because students had more time to eat. Another FSD reported an increase in total waste produced due to higher meal participation, but no change in per-student waste. A CM reported that the switch to offering breakfast in the classroom, which was made to increase participation rates after CEP adoption, led to an increase in food waste. That $\mathrm{CM}$ explained that perishable food that is sent to classrooms but not consumed must be discarded because it has been left at room temperature and may be spoiled (as opposed to if the meal had been served in the cafeteria, where it might have been temperaturecontrolled):

When delivering the breakfasts in the morning, we have to send out enough breakfasts to cover for every student who is enrolled in the school, but each day there are ... [some students who do not eat the school breakfast, and their] meals are having to go into the waste bin, because we can't take them back in and keep them, and then reuse them after just sending them out. So, I think that creates some more waste as well. - CM 17

Perceived impact on student and staff morale. Most FSDs and CMs considered the greatest benefit of CEP to be that it enabled them to feed more children. Nearly all CMs expressed gratitude that CEP had eliminated meal payment and debt, which can be stressful for parents and children alike, particularly for those with household incomes at the borderline between free and reduced-price eligibility. Most CMs described how, before CEP, they regularly encountered children whose parents had forgotten to fill out the FRPM application form or could not afford to put money into their accounts. Prior to CEP, most schools had policies that allowed students without money in their accounts to charge up to a certain number of meals, and then were required to serve students with unpaid meal debt an alternative to the hot meal such as a cheese sandwich. A few FSDs reported that a desire to eliminate this practice of providing students alternative meals, known as "meal shaming," was one of the driving factors that led their district to adopt CEP, and several FSDs and CMs reported that eliminating meal shaming had boosted both staff and student morale:

Since we had this program, the kids are very happy. We're happy too because we won't be hearing the kids say, 'I don't have no money and can't pay my lunch. My dad don't have no job. Ma don't have no income. My house no food.' ... The kids really like coming to school 
because they say, 'We come to school, I won't be hungry.' - CM 20

I think it has been positive for [cafeteria staff]. I think that no one likes to be put in a position when you're taking meals away from students. I think that's pretty demoralizing as a worker. - FSD 5

A small number of FSDs and CMs noted that CEP led to an improvement in student behavior and health. One FSD said that a school administrator had reported that he had received fewer student complaints of headaches related to hunger since the introduction of CEP. A few FSDs and CMs also reported a decrease in stigma associated with participation in school meals. Several CMs remarked that students from households with low income appeared less embarrassed when moving through the lunch line:

I'm just glad $\ldots$ all of the students is on the same level that they can come in and don't feel embarrassed about getting a free lunch...it's nothing to them now. You don't have to hear nobody in line discussing, well, 'I don't have my money.' Or, you know, 'Can you loan me this?' ... It feels good. - CM 12

When the kids do come through, it probably is better because the kid in front of them doesn't know if they got a free lunch and this kid was paying. So, I think it stopped some bullying and not getting kids picked on. - CM 18

Perceived impact on parents and broader school community. Several FSDs and CMs reported receiving strong community support for CEP and positive feedback from parents, teachers, and administrators. Many CMs described speaking with parents who were relieved that they no longer had to complete FRPM application forms or pay for student meals. One CM drew attention to how CEP helped circumvent the literacy and language barriers that prevent parents of income-eligible children from completing FRPM applications. Several CMs also noted that students were often from families with very low income, and that eliminating payment cut down on stress for parents making hard trade-offs between paying for school meals and other bills.

\section{Inner Setting: School and District Implementation Climate}

Characteristics and climate of adopting schools and districts can determine implementation success (Keith et al., 2017). This section presents perceptions among FSDs and CMs regarding how engagement from leadership and the resources and practices that were in place prior to CEP influenced implementation.

Leadership engagement. In all districts, FSDs took responsibility for leading the charge to adopt CEP, a role that typically included researching the financial implications of adoption and persuading other decision-makers. Across districts, FSDs had varying levels of autonomy regarding CEP adoption. In a small number of districts, the FSD held ultimate decision-making power regarding adoption. In most cases, however, FSDs shared decision-making power with the district superintendent or financial officers, or final decision-making power rested with the Board of Education. In districts in which the FSD did not hold primary decision-making power, FSDs emphasized the importance of being well-prepared to answer questions about the potential financial ramifications of CEP, including impacts on state and federal education funding.

Only one CM reported being consulted in the decision to adopt CEP in their school; the rest learned of the program only once the decision had been finalized. FSDs pointed to other champions, including principals, who helped encourage expansion of CEP into new schools. One FSD explained how principals throughout their district were pushing for CEP in their schools:

[Principals of] schools that didn't have CEP were approaching me and saying, 'Do I qualify for CEP? If I qualify for CEP, I want to be in CEP.' ... They were advocating on their own. One of the reasons why they were advocating is because they saw the importance of every child eating for free. They saw the issue with not having to deal with negative balances and 
not having to deal with free and reduced applications. - FSD 1

Other potential champions, such as vice principals, teachers, parent associations, and school nurses were not mentioned by any FSDs.

Existing internal resources and practices. Most FSDs and CMs reported having sufficient equipment, space, and staff to accommodate increased meal participation. Some CMs hired more staff or increased labor hours for existing staff to handle the increased participation. A small number of schools also made changes to equipment, including replacing outdated ovens and refrigerators and adding new serving lines and milk coolers. No CMs or FSDs mentioned cafeteria seating capacity constraints as an issue; several noted that their cafeterias were built to provide seating for students who previously packed their lunch. Some FSDs reported taking each school's equipment and kitchen capacity into consideration when deciding which schools to include in CEP adoption and waiting to make changes to staffing and equipment until they could see how CEP impacted meal participation rates.

CMs at schools that were previously participating in Maryland Meals for Achievement often reported having an easier time with implementation of CEP because they were already accustomed to serving universal free breakfast. Similarly, schools that had high proportion of students eligible for FRPM prior to CEP often described implementation as straightforward, with only minor changes in participation rates:

It was fairly easy. It wasn't any trouble. ... We had been doing the [universal free] breakfast meals, so it wasn't that hard, and the majority of my students anyway, they were already free, so it wasn't difficult for me. - CM 6

\section{Outer Setting: Funding and External Resources}

The external context, including federal and state policies and the political climate outside of implementing schools and districts, may influence CEP implementation (Keith et al., 2017). This section describes how policies that impact education fund- ing and reimbursement rates influence implementation decisions and highlights the external resources that FSDs and CMs used to support themselves through the implementation process.

\section{Federal, state and grant education funding. All FSDs} described concerns, both resolved and ongoing, among school and district administrators regarding how CEP may impact federal, state, and grant education funding. Schools participating in CEP no longer collect FRPM applications data, which previously served as the basis most districts used for allocating federal funding through Title I of the Elementary and Secondary Education Act (financial support for academic programming in schools with a high percentage of families with low income (Skinner \& Aussenberg, 2016)). FRPM data have also traditionally been used to determine state compensatory education funding and some grant funding (for example, for student loan forgiveness programs for teachers).

FSDs reported that the fear that CEP adoption would negatively impact their state compensatory education funding was a key barrier that prevented them from adopting CEP earlier. Most FSDs reported that their districts only felt comfortable adopting CEP after Maryland passed the HungerFree Schools Act of 2015, which fixed state compensatory education funding rates for CEP schools and thereby alleviated this concern.

Similarly, most FSDs reported that administrators in their districts were hesitant to adopt CEP due to concerns about its potential impact on Title I funding. Title I funding is allocated to school districts based on U.S. Census poverty data; therefore, the amount of federal funding each district receives is not influenced by CEP participation. However, districts must then distribute the funds to individual schools, a process that is often done based on FRPM data. A few FSDs said that after switching from using FRPM data to using ISP data to allocate funds in their district, some schools reported experiencing a disproportionate loss of Title I funding. For example, schools with a higher proportion of families with low income that are not participating in SNAP and other federal programs (e.g., immigrant families) often have lower ISPs and may experience a disproportionate change in 
the amount of Title I funding they receive. One FSD explained:

[Collecting free and reduced-price meal applications] is an incredibly important data collection process for the district in terms of garnering resources for things that are outside school meals. ... So what happened with Title I is ... we found that many of our schools that were high English language learner were dropping out of Title I at a disproportionate rate. And these students were not being counted, simply because those families are less likely to be on SNAP. This has obviously gotten worse as the years have gone by. - FSD 5

Some FSDs explained that principals whose schools had experienced reduced Title I funding continue to raise concerns about the loss of FRPM application data. One FSD also highlighted that loss of FRPM application data also presents a challenge for schools and teachers applying for external grants, which often use FRPM data as a proxy for poverty.

Schools that participate in CEP are prohibited from using USDA funds to cover the administrative costs associated with collecting and processing FRPM applications. CEP schools may collect alternate income forms using other district general funds, however, and a small number of FSDs reported that they currently collect these alternative income forms or plan to do so. One FSD explained that their district plans to use alternative income data to monitor the proportion of FRPMeligible students that are captured by the ISP, as well as to report school-level poverty rates on funding applications:

This school year coming, we are going to ask those CEP schools, even though they're on CEP ... we're gonna ask those parents to fill out free and reduced applications, because we wanna get an accurate to-date picture of where we stand in those communities, and that's more for the compensatory education funding. ... So, we are gonna ask folks to fill out an application, full well knowing that it's not gonna have any effect on whether or not their kid is gonna get a free meal. We just wanna collect it for the purposes of having data. - FSD 3

Reimbursement rates. Most FSDs explained that a school's ISP, which determines the rate at which it is reimbursed for meals served, was the most important criterion they considered when deciding which schools in their district would participate in CEP. Most FSDs were concerned about their ability to continue to participate in CEP due to dropping ISPs (and thus, reimbursement), and a few had already removed some schools within their districts from CEP or planned to in the upcoming year. FSDs attributed falling ISPs to declining national participation in SNAP and other federal assistance programs (i.e., programs from which data is drawn to calculate ISPs) associated with economic growth and increased employment at the time of study. Several FSDs also hypothesized these changes may also be driven by federal policy changes that have limited participation in federal programs and a political climate in which immigrants are concerned that federal program participation may jeopardize their immigration status.

External resources. FSDs described using a range of resources to guide them through the CEP implementation process. Most FSDs reported that the support they received from the Maryland State Department of Education was especially valuable. Several FSDs described conversations with the Maryland State Department of Education staff that helped them work through the logistics of CEP implementation and its financial implications. Only one FSD reported challenges working with the Maryland State Department of Education; they described encountering administrative obstacles when working with agency staff on CEP and other programs.

A few FSDs also used resources created by the USDA and Food Research \& Action Center, including fact sheets, webinars, and a customizable calculator to estimate the financial impact of CEP on meal reimbursement. FSDs also reported drawing on support from FSDs in other adopting districts in Maryland and neighboring states. A 
handful of FSDs of smaller districts described waiting for other districts in the state to implement first so they could learn from their experiences:

We kind of let other counties figure that out so that we didn't have to be the guinea pig. ... We saw them figuring out how to make things work. We also saw the legislature understanding what's going on and trying to adapt the regulations-Maryland regulations-to help allow the program to operate easier with less loss of income. So, it was really just watching them and then trying to utilize what they had already started. - FSD 2

\section{Implementation Process: Implementation Strategies}

This section presents strategies that FSDs and CMs highlighted as crucial to successful CEP implementation: using innovative approaches to boost school meal participation; communicating clearly and early with relevant stakeholders; launching CEP as a pilot in a small number of schools; and taking proactive steps to prepare for increased meal participation (Table 3).

First, FSDs and CMs described using diverse strategies to grow participation in the meal program. High meal participation rates, particularly among schools whose ISPs are below $62.5 \%$ and thus not reimbursed for all meals served at the free rate), is critical to achieving adequate economies of scale to remain financially solvent. A small number of FSDs and CMs reported shifting their meal service delivery style to encourage increased participation, including offering breakfast in the classroom and grab-and-go meal options. Others described working to draw in more students through improvements to the menu; identifying favorite dishes through focus groups and taste tests; offering more fruits and vegetables; and offering more hot meal options. A few FSDs and CMs also reported increasing participation in the reimbursable meal by eliminating à la carte sales or only allowing à la carte sales after all students had been served the reimbursable meal. One CM described seasonally decorating the carts on which breakfast meals were delivered to the classroom to get students excited as well as offering pizza parties in the classroom to draw in new students:
We said, hey, why don't we [offer pizza parties], since we can basically treat every student to a slice of pizza and a meal, and this exposes those other kids who are still packing for whatever reason ... Maybe a little bit of extra work goes into that. But I feel like it pays dividends in the long run for many reasons, like I said, not just the participation issue but making sure that those students, you know, are aware that maybe school lunch isn't quite so bad. - CM 7

Second, FSDs emphasized the importance of good communication with school administrators, parents, and the broader community. A small number of FSDs and CMs reported that parents were confused about how CEP functioned, particularly when they had children who transferred or advanced from a CEP school to a non-CEP school within the district, or when siblings attended schools with and without CEP. Schools participating in CEP are no longer required to collect FRPM applications from students, yet one FSD described misunderstandings among school administrative staff about whether students were required to complete FRPM applications, which may have contributed to confusion among parents.

CMs largely reported that they did not engage in communication with parents about CEP (except when asked directly or when confused parents tried to send in money to pay for their child's meals), but rather left communication to FSDs and school principals. FSDs described using a range of channels to communicate with parents about CEP, including the school website, newsletters, robocalls, media coverage, signs throughout the school, emails and letters, social media, and announcements at Back-to-School nights.

One FSD described also taking parental confusion into account when selecting which schools in the district would adopt CEP; in their district, they adopted CEP in schools that were linked feeder schools (i.e., offering CEP in an elementary school and the middle school into which the elementary school fed). Most FSDs and CMs noted that parental confusion decreased over time as the community came to understand the program better.

A few FSDs recommended implementing CEP 
in a small number of schools at first, monitoring the impact on budget and meal participation rates, and then expanding the program to other schools in the district. One FSD explained that it was easier to sell CEP to their Board of Education as a pilot program:

We presented the CEP Provision to our Board of Education as a pilot program. ... And then, each year after that, we started bringing more schools into the program. ... The pilot piece came in as a test to make sure that we could pull off the program and that it would not be an impact to other departments in the school district, such as our Title I department and our finance department when it came to [state compensatory education] funding. - FSD 1

Finally, several CMs described a short adjustment period when CEP was first introduced during which they constantly monitored food inventory and staffing to ensure they were meeting the increased demand for school meals. CMs explained the importance of ordering enough food in the first few weeks to serve the entire student body and then recalibrating their orders to more accurately meet the demand after a few weeks. Most CMs had been in their role for many years and felt confident in their ability to successfully navigate these changes.

\section{Discussion}

Overall, FSDs and CMs reported positive perceptions of CEP implementation and highlighted several benefits of CEP, including its potential to increase meal participation, reduce student stigma, alleviate financial stress among parents, and boost staff morale. Though FSDs and CMs provided mixed reports about the impact of CEP on their overall budget, line flow, and workload, all expressed gratitude for CEP and a desire to continue participating. FSDs and CMs also described several best practices that can be adapted by other districts and schools.

Perceptions regarding the ease of CEP implementation and the degree to which CEP affected key outcomes appeared to differ, in part, based on district and school characteristics. Districts and schools that were previously participating in the Maryland Meals for Achievement universal free breakfast in the classroom program or that had a large proportion of students previously receiving FRPM often described CEP implementation as easier than others, but also saw less dramatic shifts in outcomes such as meal participation rates. Districts that opted into CEP district-wide also found implementation easier and saw greater benefits, including reductions in the administrative work associated with processing meal applications. FSD and $\mathrm{CM}$ perceptions were highly complementary, with no instances in which most CMs felt one way and most FSDs another, suggesting that, by-andlarge, FSDs have a clear picture of the relevant dayto-day operations within schools.

Perceptions among some FSDs and CMs that CEP produced improvements in student behavior, decreased stigma, and fewer instances of bullying are supported by emerging quantitative research indicating that CEP adoption may lead to fewer disciplinary referrals (Gordon \& Ruffini, 2018; Kho, 2018). Unlike two previous studies that examined universal free breakfast programs, however, most FSDs and CMs in the present study reported no perceived change in wasted food (Bernstein et al., 2004; Blondin et al., 2015). Changes in wasted food in the context of universal free meal programs have not been assessed quantitatively; future research should use methods such as plate waste measurement to estimate changes in wasted food. Considering food waste is pervasive-both in the US overall, and in school meal programs in particular (in most studies, 30\% or more of food served in schools is wasted) — strategies to reduce wasted food in the school context should also be further explored (Shanks, Banna, \& Serrano, 2017). Reports of financial impacts of CEP on food service budgets differed across districts; quantitative research is needed to measure the impacts of CEP on districts' budgets. Analyses should consider changes in food service operational costs and revenue, as well as federal, state, and grant education funding, and the degree to which these impacts differ based on school and district characteristics.

Most participants reported that CEP did not lead to change in policies and practices related to 
purchasing from local or regional farmers. At the same time, a small number of participants reported serving more processed and packaged foods.

Schools experiencing increased revenue and meal participation rates due to CEP participation have a unique opportunity to source more whole foods from local producers. A robust statewide farm-toschool initiative could help CEP districts connect to more local producers; currently, the Maryland farm-to-school program has no designated funding (Maryland Department of Agriculture, n.d.). Schools may be able to emulate districts such as Novato Unified School District in Novato, California, which implemented policies that aimed to not only increase sourcing of local foods but also to decrease wasted food and reduce consumption of ultra-processed foods (Brenner, 2018).

Among schools with ISPs below 62.5\%, maintaining high meal participation rates is critical to making CEP financially sustainable. Some of the strategies that FSDs and CMs described as successful in growing meal participation rates, however, may have negative unintended consequences for student health and nutrition. For example, while research does show that breakfast in the classroom is associated with increased meal participation, there is mixed evidence regarding the impact of breakfast in the classroom on diet quality and obesity (Baxter et al., 2010; Polonsky et al., 2019; Soldavini \& Ammerman, 2019; Van Wye, Seoh, Adjoian, \& Dowell, 2013). Food service staff at CEP-participating schools seeking to grow meal participation rates should weigh potential nutritional impacts.

\section{Implications for Policy and Practice}

FSDs and CMs highlighted barriers and facilitators to implementation at each level of the adapted Consolidated Framework for Implementation Research, providing insight into potential policy and programmatic interventions that may promote CEP uptake. First, among the chief barriers to CEP adoption cited by FSDs were concerns regarding the financial impacts of CEP on federal, state, and grant funding. This barrier was also identified in the USDA report assessing implementation during the initial rollout of CEP (Logan et al., 2014); the current study provides evidence that this barrier persists despite USDA guidance issued in the intervening years that outlines alternate strategies districts can use to allocate Title I funding (United States Department of Agriculture Food and Nutrition Service, 2015). Indeed, some districts in this study were already collecting, or were considering plans to collect alternate income forms to document FRPM eligibility, an administrative undertaking that requires considerable time and money, and which CEP was designed to eliminate. Schools using alternative income forms may also be unable to gather complete and reliable information because parents have less incentive to complete the form since it does not directly affect their child's ability to receive school meals. To alleviate concerns about loss of FRPM data, USDA, state education agencies, and anti-hunger advocates could consider new strategies to strengthen and clarify messaging about CEP's impact on Title I funding. Given FSDs reports that the state education agency and FSDs from other districts served as key resources during the implementation process, using these messengers to educate FSDs and other administrators at prospective CEP schools about financial implications may help promote uptake. Grant funders could also consider using alternate measures of poverty in place of FRPM eligibility data such as ISP or composite measures using multiple types of poverty data (Toward an Accurate Count of Low-Income Students, 2019).

Second, most FSDs reported feeling comfortable adopting CEP only after Maryland passed legislation that protects CEP schools from a change in state compensatory education funding. In other states with low CEP adoption rates, anti-hunger advocates and policymakers could explore if similar state-level legislative changes may also encourage participation among late adopters. Laws used in other states to promote CEP adoption, such as California's SB 138, which requires schools with ISPs above $62.5 \%$ to participate in a universal free meal provision and to use Medicaid data to directly certify students, could also be considered to promote uptake (California State Senate Bill 138: Universal Meal Service - School Nutrition, 2017).

Finally, this study found that declining ISPs were of major concern to districts considering recertifying for an additional four-year cycle of 
CEP or adding new schools to CEP. Due to rising rates in unemployment and increased participation in federal benefit programs associated with the COVID-19 pandemic, however, ISPs have risen for SY 2020-21 (Rosenbaum, 2020). As a result, some schools have become newly eligible for CEP and, for others, CEP has become more financially favorable. Importantly, however, ISPs declines during the study period may have been attributable in part to policies that make it more challenging for income-eligible families to enroll in public benefit programs (for example, the Categorical Eligibility for SNAP proposed rule (Revision of Categorical Eligibility in the Supplemental Nutrition Assistance Program (SNAP), 2019)) or promote fear that participation in these programs will negatively affect immigration status (for example, the revised Inadmissible on Public Charge Grounds final rule (U.S Citizenship and Immigration Services, 2020)). The Inadmissible on Public Charge Grounds rule was rescinded in March 2021 (Kruzel, 2021), but future policies could be examined to avoid negative impacts on school meal access. Improvements to direct certification systems that identify students as categorically eligible for free meals are also warranted nationwide to ensure ISPs accurately reflect student need; in SY 2016-17, states failed to certify an average of $8 \%$ of children directly eligible for free meals (United States Department of Agriculture, 2018). Additionally, 19 states are authorized by USDA to use income data available in Medicaid administrative records in their direct certification systems; research suggests that extending this practice to other states, including Maryland, may increase ISPs and better reflect poverty levels in different communities (Hulsey et al., 2019).

With the recent dramatic rise in poverty and hunger among households with children due to the COVID-19 pandemic, school meal programs serve an increasingly important role in feeding children. Because CEP schools were serving universal free meals prior to the pandemic, many were able to quickly adapt to COVID-19-related school closures by setting up emergency universal free meal distribution sites or providing meal delivery to all students at home (Kinsey et al., 2020). In light of ongoing COVID-19-related school closures, the USDA has authorized states to request waivers to serve universal free meals through the USDA Summer Food Service Program or Seamless Summer Option through September 30, 2021 (United States Department of Agriculture, 2020). Given the nation is likely to continue to grapple with social and economic ramifications of the pandemic long beyond the end of the school year, adoption of CEP has been identified as a strategy for schools to continue to serve universal free meals into the future. The best practices for implementation identified in this study can guide these schools as they launch their CEP programs.

\section{Limitations}

This study has some limitations. First, nearly one quarter of contacted FSDs and CMs declined to participate in this study. While the FSDs and CMs who declined to participate in the study represent schools and districts that are demographically similar to participants, those that declined may be different in unobservable ways. This study is strengthened by inclusion of perspectives from FSDs and CMs representing ten of the twelve CEP-participating districts in Maryland, and a range of geographies, school levels (elementary, middle, high, and other), and number of years participating in CEP. Second, this study only included districts and schools that were participating in CEP in SY 2018-19. Future research should consider the perspectives of those districts or schools that are eligible for CEP but not participating, as well schools that previously participated in CEP but have since opted out of the program.

\section{Conclusions}

This study is the first since nationwide rollout of CEP to qualitatively explore implementation in schools and the only study to include perspectives from both FSDs and CMs, who provide unique insight into CEP implementation at the school and district levels. Barriers to CEP implementation identified in this study, including concerns regarding CEP's impact on federal, state, and grant funding, and declining ISP rates provide insight into policy interventions that may promote uptake. Best practices for implementation identified in this study, including strong communication with parents, creative strategies to boost student meal 
participation, and elimination of PINs to streamline flow through the lunch line, can be adapted by other districts. Strategies to grow meal participation should, however, be designed with potential impacts on nutrition and health in mind. Finally, this study adds depth and nuance to the growing body of quantitative literature that has documented the benefits of CEP for student health, learning, and behavior (Cohen, Hecht, McLoughlin, Turner, \& Schwartz, 2021; Hecht et al., 2020). Further quantitative research on the impact of CEP on school finances and other components of the food system, including wasted food and purchasing relationships between schools and local and regional farmers, would complement findings presented in this study. Considering the potential benefits of CEP, policymakers, advocates, and state education agencies could use results from this study to better support successful implementation in schools that have adopted CEP, and design strategies to encourage adoption among eligible schools.

\section{References}

Alaimo, K., Olson, C. M., \& Frongillo, E. A. (2001). Food insufficiency and American school-aged children's cognitive, academic, and psychosocial development. Pediatrics, 108(1), 44-53. https://pediatrics.aappublications.org/

Alaimo, K., Olson, C. M., Frongillo, E. A., \& Briefel, R. R. (2001). Food insufficiency, family income, and health in US preschool and school-aged children. American Journal of Public Health, 91(5), 781-786. https://doi.org/10.2105/AJPH.91.5.781

Bartfeld, J. S., \& Ahn, H.-M. (2011). The School Breakfast Program strengthens household food security among lowincome households with elementary school children. The Journal of Nutrition, 141(3), 470-475. https://doi.org/10.3945/jn.110.130823

Bauer, L. (2020). The COVID-19 crisis has already left too many children hungry in America. Brookings. https://www.brookings.edu/blog/up-front/2020/05/06/the-covid-19-crisis-has-already-left-too-many-childrenhungry-in-america/

Baxter, S. D., Hardin, J. W., Guinn, C. H., Royer, J. A., Mackelprang, A. J., \& Devlin, C. M. (2010). Children's body mass index, participation in school meals, and observed energy intake at school meals. The International Journal of Behavioral Nutrition and Physical Activity, 7, 24. https://doi.org/10.1186/1479-5868-7-24

Bernstein, L. S., McLaughlin, J. E., Crepinsek, M. K., \& Daft, L. M. (2004). Evaluation of the School Breakfast Program Pilot Project: Final Report. Special Nutrition Programs. Report Number CN-04-SBP. Nutrition Assistance Program Report Series. USDA, Food and Nutrition Service. https://eric.ed.gov/?id=ED486532

Blondin, S. A., Djang, H. C., Metayer, N., Anzman-Frasca, S., \& Economos, C. D. (2015). 'It's just so much waste.' A qualitative investigation of food waste in a universal free School Breakfast Program. Public Health Nutrition, 18(9), 1565-1577. https://doi.org/10.1017/S1368980014002948

Brenner, K. (2018). Novato schools break new nutritional ground. Marin Independent Journal. https://www.marinij.com/2018/12/15/novato-schools-break-new-nutritional-ground/

California State Senate Bill 138: Universal Meal Service-School Nutrition, (2017). https://www.cde.ca.gov/ls/nu/sn/mbsnp012018.asp

Cohen, J. F. W., Hecht, A. A., McLoughlin, G. M., Turner, L., \& Schwartz, M. B. (2021). Universal school meals and associations with student participation, attendance, academic performance, diet quality, food security, and body mass index: A systematic review. Nutrients, 13(3), 911. https://doi.org/10.3390/nu13030911

Congressional Research Service. (2020). Unemployment rates during the COVID-19 pandemic: In brief. https://fas.org/sgp/crs/misc/R46554.pdf

Cook, J. T., \& Frank, D. A. (2008). Food Security, Poverty, and Human Development in the United States. Annals of the New York Academy of Sciences, 1136(1), 193-209. https://doi.org/10.1196/annals.1425.001

Food Research \& Action Center. (2020). Community eligibility: The key to hunger-free schools school year 2019-2020. https://frac.org/research/resource-library/community-eligibility-the-key-to-hunger-free-schools-school-year-2019$\underline{2020}$ 
Fox, M. K., \& Gearan, E. (2019). School Nutrition and Meal Cost Study. Volume 4: Student participation, satisfaction, plate waste, and dietary intakes. United States Department of Agriculture. https://www.fns.usda.gov/school-nutrition-and-meal-cost-study

Glewwe, P., Jacoby, H. G., \& King, E. M. (2001). Early childhood nutrition and academic achievement: A longitudinal analysis. Journal of Public Economics, 81(3), 345-368. https://doi.org/10.1016/S0047-2727(00)00118-3

Gordon, N. E., \& Ruffini, K. J. (2018). School nutrition and student discipline: Effects of schoolwide free meals (Working Paper No. 24986). National Bureau of Economic Research working paper. https://doi.org/10.3386/w24986

Toward an Accurate Count of Low-Income Students, Connecticut General Assembly (2019) (testimony of Erica Greenberg).

Gundersen, C., \& Ziliak, J. P. (2015). Food insecurity and health outcomes. Health Affairs, 34(11), 1830-1839. https://doi.org/10.1377/hlthaff.2015.0645

Hecht, A. A, Pollack Porter, K. M., \& Turner, L. (2020). Impact of the Community Eligibility Provision of the Healthy, Hunger-Free Kids Act on student nutrition, behavior, and academic outcomes: 2011-2019. American Journal of Public Health, 110(9), 1405-1410. https://doi.org/10.2105/AJPH.2020.305743

Huang, J., \& Barnidge, E. (2016). Low-income children's participation in the National School Lunch Program and household food insufficiency. Social Science \& Medicine, 150, 8-14. https://doi.org/10.1016/i.socscimed.2015.12.020

Hulsey, L., Gothro, A., Leftin, J., Estes, B., Smither-Wulsin, C., Washburn, L., Thomason, J., \& Golinelli, D. (2019). Evaluation of the Direct Certification with Medicaid for Free and Reduced-Price Meals Demonstration-Year 1. United States Department of Agriculture. https://www.fns.usda.gov/cn/evaluation-direct-certification-medicaid-free-and-reduced-price-meals

Jyoti, D. F., Frongillo, E. A., \& Jones, S. J. (2005). Food insecurity affects school children's academic performance, weight gain, and social skills. The Journal of Nutrition, 135(12), 2831-2839. https://doi.org/10.1093/in/135.12.2831

Keith, R. E., Crosson, J. C., O’Malley, A. S., Cromp, D., \& Taylor, E. F. (2017). Using the Consolidated Framework for Implementation Research (CFIR) to produce actionable findings: A rapid-cycle evaluation approach to improving implementation. Implementation Science, 12(1), 15. https://doi.org/10.1186/s13012-017-0550-7

Kho, A. (2018). Three Essays on School Reform [Dissertation]. Vanderbilt University.

Kinsey, E. W., Hecht, A. A., Dunn, C. G., Levi, R., Read, M. A., Smith, C., Niesen, P., Seligman, H. K., \& Hager, E. R. (2020). School closures during COVID-19: Opportunities for innovation in meal service. American Journal of Public Health, 110(11), 1635-1643. https://doi.org/10.2105/AJPH.2020.305875

Kruzel, J. (2021, March 11). Biden rescinds Trump's 'public charge' rule. The Hill. Retrieved from https://thehill.com/regulation/court-battles/542860-biden-rescinds-trumps-public-charge-rule

Logan, C. W., Connor, P., Harvill, E. L., Harkness, J., Nisar, H., Checkoway, A., Peck, L. R., Shivji, A., Bein, E., Levin, M., \& Enver, A. (2014). Community Eligibility Provision Evaluation. United States Department of Agriculture, Food and Nutrition Service. https://fns-prod.azureedge.net/sites/default/files/CEPEvaluation.pdf

Maryland Association of Boards of Education. (2019). Maryland budget bighlights fiscal year 2019. https://www.mabe.org/wp-content/uploads/2012/01/BudgetHighlightsFY19EDUC.pdf

Maryland Department of Agriculture. (n.d.). Farm to school_FAQ. Retrieved November 18, 2020, from https://mda.maryland.gov/farm to school/Pages/Farm-to-School---FAQ.aspx

Maryland State Department of Education. (2015, September 18). More than 200 Maryland schools implement community eligibility for 2015-16. https://news.maryland.gov/msde/09 18 2015/

Maryland State Department of Education. (2020a). Community Eligibility Provision (CEP) data. http://marylandpublicschools.org/programs/Pages/School-Community-Nutrition/CEPData.aspx

Maryland State Department of Education. (2020b). MMFA school participation data. http://www.marylandpublicschools.org/programs/Pages/School-Community-Nutrition/MMFAData.aspx

Moore, Q., Hulsey, L., \& Ponza, M. (2009). Factors associated with school meal participation and the relationship between different participation measures_Final report (p. 173). Mathematica Policy Research.

National Center for Education Statistics, U.S. Department of Education. (2020). Common Core of data. https://nces.ed.gov/ccd/ 
Polonsky, H. M., Bauer, K. W., Fisher, J. O., Davey, A., Sherman, S., Abel, M. L., Hanlon, A., Ruth, K. J., Dale, L. C., \& Foster, G. D. (2019). Effect of a breakfast in the classroom initiative on obesity in urban school-aged children: A cluster randomized clinical trial. JAMA Pediatrics, 173(4), 326-333. https://doi.org/10.1001/jamapediatrics.2018.5531

Poppendieck, J. (2010). Free for All: Fixing School Food in America (1st ed.). University of California Press. https://www.jstor.org/stable/10.1525/j.ctt1pn8qf

Public Law 111-296. Healthy Hunger-Free Kids Act of 2010, 42 USC 1751, \$203., 111th Congress (2010).

Revision of Categorical Eligibility in the Supplemental Nutrition Assistance Program (SNAP), (2019). https://www.federalregister.gov/documents/2019/07/24/2019-15670/revision-of-categorical-eligibility-in-thesupplemental-nutrition-assistance-program-snap

Rosenbaum, D. (2020). SNAP is responding to increased need, early evidence shows. Center on Budget and Policy Priorities. https://www.cbpp.org/blog/snap-is-responding-to-increased-need-early-evidence-shows

Ryu, J.-H., \& Bartfeld, J. S. (2012). Household food insecurity during childhood and subsequent health status: The Early Childhood Longitudinal Study_kindergarten cohort. American Journal of Public Health, 102(11), e50-e55. https://doi.org/10.2105/AJPH.2012.300971

School Nutrition Association. (2019). School meal trends \& stats. https://schoolnutrition.org/aboutschoolmeals/schoolmealtrendsstats/

Shanks, C. B., Banna, J., \& Serrano, E. L. (2017). Food waste in the National School Lunch Program 1978-2015: A systematic review. Journal of the Academy of Nutrition and Dietetics, 117(11), 1792-1807. https://doi.org/10.1016/j.jand.2017.06.008

Skinner, R. R., \& Aussenberg, R. A. (2016). Overview of ESEA Title I-A and the School Meals' Community Eligibility Provision. Congressional Research Service. https://www.everycrsreport.com/reports/R44568.html\#Content

Soldavini, J., \& Ammerman, A. S. (2019). Serving breakfast free to all students and type of breakfast serving model are associated with participation in the School Breakfast Program. Journal of the Academy of Nutrition and Dietetics, 119(7), 1142-1149. https://doi.org/10.1016/j.jand.2019.03.001

The Hunger-Free Schools Act of 2015, Maryland HB 965, (2015). http://mgaleg.maryland.gov/2015RS/fnotes/bil_0005/hb0965.pdf

Tracy, S. (2013). Qualitative research methods. Wiley-Blackwell.

United States Department of Agriculture [USDA]. (2018). Direct certification in the National School Lunch Program Report to Congress: State implementation progress, school year 2015-2016 and 2016-2017. https://fns-prod.azureedge.net/sites/default/files/resource-files/NSLPDirectCertification2016.pdf

USDA. (2020). Nationwide waiver to allow SFSP and Seamless Summer Option operations through SY 2020-2021-Extension. United States Department of Agriculture. https://www.fns.usda.gov/cn/covid-19-response-59

USDA Economic Research Service [USDA ERS]. (2019). National School Lunch Program. https://www.ers.usda.gov/topics/food-nutrition-assistance/child-nutrition-programs/national-school-lunchprogram.aspx

USDA ERS. (2019, September 4). Key statistics \& graphics: Food security status of U.S. households with children in 2018. https://www.ers.usda.gov/topics/food-nutrition-assistance/food-security-in-the-us/key-statisticsgraphics/\#children

USDA Food and Nutrition Service. (2015, April 30). Updated Title I guidance for schools electing Community Eligibility. https://www.fns.usda.gov/updated-title-i-guidance-schools-electing-community-eligibility

U.S Citizenship and Immigration Services. (2020, March 4). Public charge. https://www.uscis.gov/greencard/public-charge

Van Wye, G., Seoh, H., Adjoian, T., \& Dowell, D. (2013). Evaluation of the New York City Breakfast in the Classroom Program. American Journal of Public Health, 103(10), e59-e64. https://doi.org/10.2105/AJPH.2013.301470

Weinreb, L., Wehler, C., Perloff, J., Scott, R., Hosmer, D., Sagor, L., \& Gundersen, C. (2002). Hunger: Its impact on children's health and mental health. Pediatrics, 110(4), e41. https://doi.org/10.1542/peds.110.4.e41 


\section{Appendix. Guide for In-Depth Interviews}

Interviewer: The questions I am going to ask you today are about the Community Eligibility Provision, the provision of the National School Lunch and School Breakfast Programs that allows schools/ school systems like yours to serve universal free meals to all students. Your school/school system participates in the Community Eligibility Provision. Because of the provision, all students at participating schools receive school meals for free without having to turn in any forms to prove their income.

\section{Introductory Questions:}

1. What is your current role in your school/school system?

2. How long have you worked in your current role? In this school system?

3. Your school/school system has been offering universal free breakfast and lunch through the Community Eligibility Provision (CEP) since [X year]. Did your school/school system offer universal free breakfast or lunch to students through a different program before that? (for example, Maryland Meals for Achievement)

4. [Food Service Director only] Do all of the schools in your school system participate in CEP?

a. If no, why not? If no, how did your school system decide which schools would adopt CEP?

b. If your school system phased in CEP, how did you decide which schools would adopt first?

5. [Food Service Director only] Tell me about the process of deciding to adopt CEP in your school system. Who was involved in making that decision? What factors did you consider when deciding to adopt CEP?

6. [Cafeteria Manager only] How did you first learn that your school was considering making the switch to CEP? Were you consulted about the decision? What did you think of the decision?

7. I am interested in understanding how you felt about how the switch to offering universal free meals. Can you tell me what you think about how the switch to universal free meals went?

\section{Facilitators and Barriers:}

1. Can you tell me about any factors that have helped or made it easier for your school/school system to make the switch to offering universal free meals? To operate the program now? (e.g., champions, positive budget impacts)

2. Was there anyone in your school/school system that championed, or pushed, the change to universal free meals?

a. If yes, what did that champion do?

3. Can you tell me about challenges your school/school system faced in making the switch to offering universal free meals, if any?

4. Are there any ongoing issues your school/school system faces in serving universal free meals? (e.g., community buy-in, student participation)

5. How, if at all, did you communicate with parents and students about the switch to universal free meals?

6. [Food Service Director only] Can you comment on any schools in your school system that had a harder or easier time than others making the switch to offering universal free meals? What do you think has made it harder or easier for some schools than others? 
7. Can you tell me about the feedback you've received about the switch to universal free meals, if any, from people in your community such as parents, students, teachers, principals? [Prompt: Has there been any confusion?]

\section{Operational Impacts:}

1. What impact has offering universal free meals had on the total number of students participating in breakfast? Lunch? An estimate is ok.

2. [If they experienced an increase in meal participation] Did your school/school system have the resources such as staff, cafeteria space, and equipment to handle more students participating in the school meals?

a. If no, how have you addressed these resource limitations?

3. [Food Service Director only] How, if at all, has the switch to universal free meals affected the administrative work required to operate the school meals program?

4. [Cafeteria Manager only] When your school first started offering universal free meals, before you knew what the impact might be on your participation rates, what steps, if any, did you take to prepare and get ready for the switch? [Prompt: How did you think about decisions like how much food to order and how many staff to have working in the first few weeks?]

5. What did food service staff at your school/school system think about the change to offering universal free meals? What do they think now?

a. What impact has offering universal free meals had on your food service staff? (e.g., workload, attitudes, cohesion)

6. [Food Service Director only] In what ways has the switch to universal free meals impacted your overall school system budget? [Prompt: i.e., through changes in participation rates, staffing needs, reimbursement, snack sales]

a. If positively, how has your school system used the increased

b. revenue?

c. If negatively, how has your school system compensated for the decreased revenue?

d. If no change, how did you maintain your budget with the change in the reimbursement structure?

e. What impact has offering universal free meals had on your snacks sales?

f. What impact has the switch had on your unpaid meal debt? Have you changed any of your practices as a result? (e.g., giving students a different meal who could not pay?)

7. How has the universal free meals program affected meal service operations at your school/school system?

a. What changes, if any, have you made to your meal counting process? (e.g., headcount, point-of-service) Why did you chose to use this process?

b. What impact has offering universal free meals had on the way that students move through the cafeteria line? On the amount of time they have to eat?

c. What changes, if any, has your school system made to the way in which breakfast and lunch are served (e.g., breakfast in the classroom, grab and go) because of the switch to universal free meals?

d. What changes, if any, has your school system made to types of food you serve because of the switch to universal free meals? 
e. What impact has offering universal free meals had on the amount of food each student eats? The healthfulness of the foods they eat?

f. In your opinion, what impact, if any, has offering universal free meals had on student attitudes or behavior?

8. What changes, if any, have you noticed in the amount of food discarded each day since your school/school system began offering universal free meals? [Prompt: have the number of bags of trash you collect daily changed?]

a. If yes, how? Why do you think this has changed?

9. Does your school/school system have relationships with any local or regional farmers?

a. If yes, what impact has offering universal free meals had on your school/school system's ability to purchase from local or regional farmers?

10. [Cafeteria managers only] What strategies, if any, have you used to try to increase participation in your meal program because of the switch to the universal free meals program?

\section{Other School Concerns:}

1. [Food Service Director only] To your knowledge, has the switch to universal free meals impacted Title 1 distributions to schools in your school system?

2. Some schools use their free and reduced-price meal applications to certify students to receive other education benefits such as such as discounted prom tickets or yearbooks. To your knowledge, have administrators at your school/school system raised concerns about the impact of not collecting free and reduced-price meal applications on their ability to administer these benefits?

3. [Food Service Director only] School systems need to re-apply to participate in CEP every four years. Does your school system plan to re-apply? Why or why not?

a. If yes, what challenges, if any, do you foresee with the process of re-applying?

4. [Food Service Director only] Can you comment on changes, if any, you've seen to your identified student percentage (ISP), or the number of students categorically eligible for school meals since you first opted in? How often do you preform direct certification match searches?

\section{Closing:}

1. Do you have any advice for other schools/school systems considering making the switch to universal free meals?

2. Which resources, if any, have you or schools in your school system used to guide you in the switch to offering universal free meals? (e.g., websites, toolkits, advocates, groups) Are there any other resources you would have liked to have to guide you?

3. Is there anything else you would like to share with me regarding how the universal meal program has been rolled out at your school/school system? 